\title{
Is the Taxonomic Composition of Landbird Communities in Mexico Predictable?
}

\author{
Héctor Gómez de Silva*
}

Huatusco 13, Departamento 5; C.P. 06760 - México, D.F. Mexico

\begin{abstract}
Some bird families are more widespread than others both in geography and in habitat use (high-incidence families). The number of Mexican species in a bird family was found to be strongly correlated with the number of communities that possess representatives of that family. This effect did not result from a higher probability of larger families having more widespread species or having species with broader diets or habitat preferences, nor from body size, abundance or clutch size, other factors which tend to correlate with the incidence of species. Instead, number of species per se (a trait of families) strongly influenced family incidence and thereby community composition. Therefore, community composition is influenced not only by ecological assembly rules at the species level, but also by the result of macroevolutionary processes above the species level. This pattern may be related to species-area curves and provides an opportunity for coevolution to occur even in situations in which species-specific coadaptation is not possible. This pattern increases the predictability of species composition of communities.
\end{abstract}

\section{INTRODUCTION}

Are ecological communities random assemblages of species or on the contrary, is community composition predictable? (Or is reality somewhere in between?) Predictable patterns would argue for deterministic rules of assembly; indeed empirical patterns are thought to be the outcome of "assembly rules" $[1,2]$.

That biotic communities with unused resources are exceptional is one consequence of the ideal free distribution of populations [3]. Gómez de Silva and Medellín [4] tested this prediction among diurnal landbirds of Mexico and found that, except for a small number of "outliers" correlated with extremely harsh climates that limit bird presence and except for completely treeless areas, communities contained species from all 12 guilds that correspond to widespread food resources (nectar, seeds and fruits, vertebrates, carrion and different types of invertebrates).

An additional pattern among Mexican landbirds was that 17 families recurred in all or practically all communities [5]. Whatever factors accounted for the families' different frequency of occurence among communities (hereafter termed "incidence") was independent of resource utilization because there was no 1:1 correspondence between food guilds and taxonomic groups of Mexican birds. No food guild corresponded to only a single family (instead, the food guilds were represented by species of from 2 to 27 families and most families regularly use resources pertaining to from 2 to 10 food guilds, unpublished data). Family incidence, in turn, strongly influences community composition.

*Address correspondence to this author at the Huatusco 13, Departamento 5; C.P. 06760 - México, D.F. Mexico; Tel: + (52) (55) 557400 20; E-mails: hector.gomezdesilva@gmail.com and

hgomez@miranda.ecologia.unam.mx
The incidence of families may be correlated with traits of their constituent species or with emergent properties of the families themselves. For example, since species incidence seems to be positively correlated with niche breadth (number of food types), body size, abundance, and clutch size [6], then families containing species that on average have broader diets or are larger, more abundant and/or produce larger clutches may be likely to be more ubiquitous.

On the other hand, the number of species in the family may influence family incidence if species-rich families are able to spread more widely and occupy a wider variety of habitats. Furthermore, the historical biogeography of a family may influence that family's incidence, especially in a region such as Mexico with a mix of faunas of different geographical origin (Nearctic and Neotropical). This article explores the observed pattern of family incidence among Mexican landbirds searching for factors in addition to resource use that influence community composition.

\section{MATERIALS AND METHODOLOGY}

The incidence of each landbird family in Mexico was estimated by counting the number of well-known landbird communities (see [4]) in which a family was recorded. Cornell Lab of Ornithology [7] was followed for the familylevel taxonomy, with the exceptions that the content of families Parulidae, Thraupidae and Cardinalidae follow Klicka et al. [8], but with Saltator retained in Cardinalidae. On the other hand, species-level taxonomy followed Howell \& Webb [9].

Species niche breadth, body size, abundance, and clutch size was based on data from the literature [9-16]. Because the last three variables are difficult to quantify in a meaningful way because of intraspecific variation (e.g., clutch size and abundance within species vary according to the suitabi- 
lity of the local environment [6]), these three were examined in a qualitative way to test for any possible correlation with family incidence. Biogeographical influences were likewise examined in a qualitative way, based on current species diversity; particularly whether the family is cosmopolitan, limited to the New World, or whether species richness tends to increase north of or south of Mexico based on [7, 13].

To explore the relationship between family incidence and the quantifiable traits species incidence, species niche breadth (mean number of food guilds per species in the family), species habitat breadth, and number of species in the family, linear regression tests were applied using the software Sigmastat (version 1.0), with family incidence as the dependent variable and with all combinations of the independent variables. When the data did not pass the tests of normality or homoscedasticity, the independent variable was $\log _{10}$-transformed. For each test, the best regression was considered that with the highest $\mathrm{r}^{2}$, highest power of test and lowest $p$.

Species niche breadth was estimated as the mean number of food guilds (sensu [4]) per species. Species incidence was the average of the number of localities where each species in the family was recorded [4]). To estimate species habitat breadth, a classification of habitat types as they affect land bird distribution was attempted. To arrive at this classifica- tion, similarity values (Simpson's index) between all pairs of communities in the data base of Gómez de Silva and Medellín [4] were calculated and then a cluster analysis (Ward's method) was performed using the software JMP (version 3.1). Simpson's similarity index was chosen because it is insensitive to differences in species richness between localities compared [17], and is therefore the most useful similarity index for sets of localities having a nested subset structure (a situation prevalent among ecological communities; [18,19]). The resulting classification considered four habitat-types based on the two most basal forks of the dendrogram (48\% similarity): desert scrub, temperate forest, tropical rain forest and tropical dry forest.

The number of Mexican species in each land bird family was counted excluding species recorded in Mexico either as accidentals or only on islands [9].

\section{RESULTS}

Most species traits examined did not correlate with family incidence in the dataset. The most ubiquitous families (those with incidence $\geq 90 \%$, see Table 1) included some whose species have narrow niche breadth (specialized on single food guilds, e.g., Cathartidae, Apodidae, and Hirundinidae); the correlation was not significant $\left(\mathrm{P}=0.78, \mathrm{r}^{2}\right.$ $=0.00146$, see Table 2). The most ubiquitous families also

Table 1. Incidence of Mexican Diurnal Land Bird Families

\begin{tabular}{|c|c|c|c|c|c|}
\hline Corvidae & 100 & Trogonidae & 70 & Motacillidae & 18 \\
\hline Trochilidae & 100 & Furnariidae & 64 & Charadriidae & 16 \\
\hline Troglodytidae & 100 & Tityridae & 60 & Passeridae & 14 \\
\hline Tyrannidae & 100 & Cracidae & 58 & Formicariidae & 12 \\
\hline Cathartidae & 99 & Momotidae & 45 & Pipridae & 12 \\
\hline Emberizidae & 99 & Thraupidae & 42 & Remizidae & 12 \\
\hline Hirundinidae & 99 & Bombycillidae & 38 & Bucconidae & 9 \\
\hline Picidae & 99 & Ptilogonatidae & 36 & Phasianidae & 9 \\
\hline Cardinalidae & 95 & Paridae & 27 & Alaudidae & 6 \\
\hline Vireonidae & 94 & Tinamidae & 27 & Galbulidae & 5 \\
\hline Columbidae & 92 & Laniidae & 27 & Scolopacidae & 4 \\
\hline Turdidae & 91 & Thamnophilidae & 26 & Sturnidae & 4 \\
\hline Icteridae & 90 & Sittidae & 26 & Timaliidae & 3 \\
\hline Falconidae & 83 & Furnariidae & 22 & & \\
\hline Cuculidae & 81 & Ardeidae & 21 & & \\
\hline
\end{tabular}


included some whose species tend to have small clutch sizes and only one or two broods per year (e.g., Cathartidae, Trochilidae) and/or small mean body sizes (e.g., Trochilidae, Parulidae), and/or low mean abundances (e.g., Accipitridae, Strigidae, Corvidae), contrary to expectations if traits of species in the family determine the family's incidence. Family incidence also did not correlate with average number of habitat types used (Table 2 ). The one species trait that did correlate with family incidence was species incidence $(\mathrm{P}<0.0001$, $\mathrm{r}^{2=} 0.256$, Table 2), though the simple regression failed the homoscedasticity test. Four (24\%) of the most ubiquitous families included species whose geographic ranges encompass all of Mexico (Cathartidae, Hirundinidae, Turdidae, Parulidae).

On the other hand, family traits correlated well with family incidence. The families' extent of distribution worldwide did not correlate well with their incidence in Mexico. Whereas nine ubiquitous families (53\%) are cosmopolitan and the other eight are restricted to the New World (Table 1); and several New World families are not ubiquitous in Mexico (Tinamidae, Cracidae, Odontophoridae, Nyctibiidae, Momotidae, Bucconidae, Galbulidae, Furnariidae, Dendrocolaptidae, Thamnophilidae, Formicariidae, Cotingidae, Pipridae, Mimidae, Ptilogonatidae, Peucedramidae, Coerebidae and Thraupidae), $82 \%$ of families with incidence greater than 90\% (all except Tyrannidae, Troglodytidae and Trochilidae) are better or equally represented outside the Neotropics than inside (ie, mainly non-Neotropical).

Among the linear regressions, number of species by itself accounted for $81.27 \%$ of the variance in family incidence (Fig. 1). The logarithmic relationship can be explained by the existence of a threshold number of species above which

Table 2. Results of Correlations with Family Incidence

\begin{tabular}{|c|c|c|c|c|}
\hline & Dependent Variable & Independent Variables & $\mathbf{p}$ & $\mathbf{r}^{2}$ \\
\hline \multirow[t]{3}{*}{ Single-variable tests } & I & $\mathrm{II}^{* 1}$ & 0.0178 & 0.0962 \\
\hline & I & $\log _{10} \mathrm{IV}^{*^{2}}$ & $<0.0001$ & 0.256 \\
\hline & I & $\log _{10} \mathrm{~V}$ & 0.78 & 0.00146 \\
\hline \multirow{2}{*}{ Two-variable tests } & $\log _{10} \mathrm{I}$ & II, $\log _{10} \mathrm{IV}$ & $<0.0001$ & 0.46 \\
\hline & I & $\log _{10} \mathrm{III}, \mathrm{IV}$ & $<0.0001$ & 0.921 \\
\hline Three-variable test & I & $\log _{10} \mathrm{II}, \log _{10} \mathrm{III}, \mathrm{IV}$ & $<0.0001$ & 0.924 \\
\hline
\end{tabular}

Best linear regressions between incidence of families (variable I) and one, two and three independent variables (II=average number of habitat types per species, III=number of species in the family, IV=average number of localities per species, and $\mathrm{V}=$ mean number of food guilds per species).

$*^{1}$ failed normality; low power of test $(0.6623)$.

$*^{2}$ failed homoscedasticity; high power of test $(0.9849)$
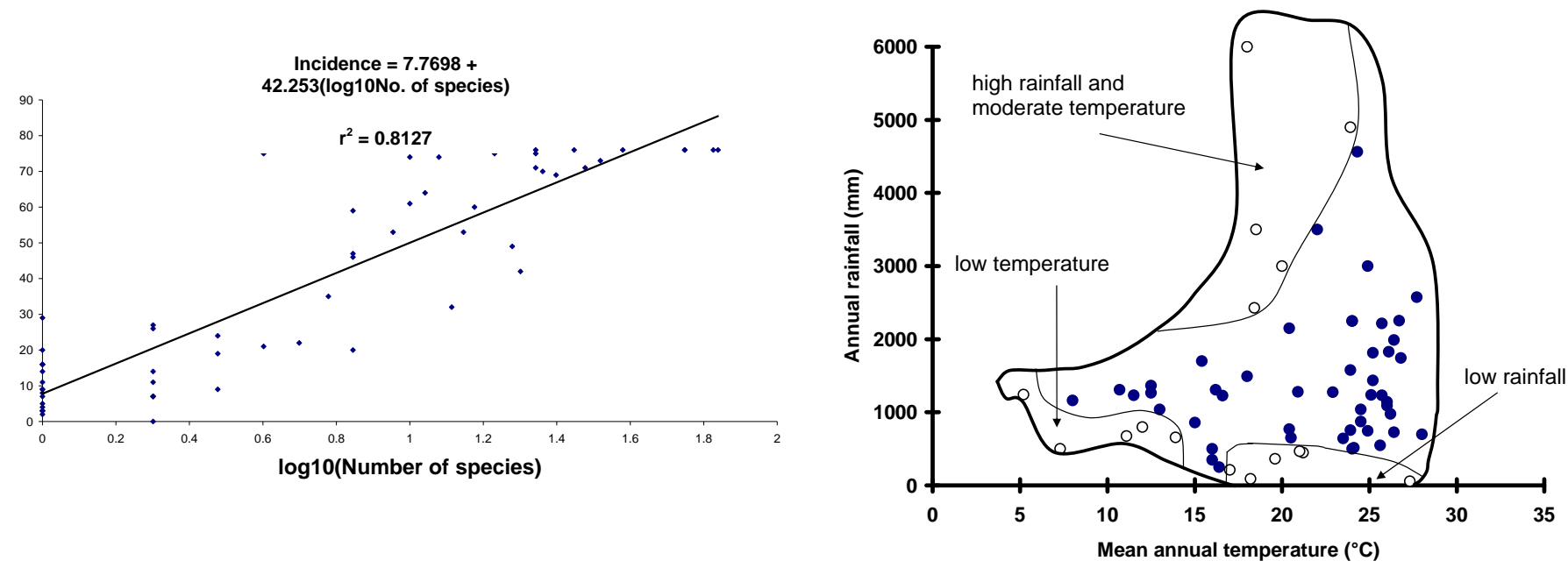

Fig. (1). Incidence of Mexican diurnal landbird families versus number of species. 
families are ubiquitous: all 13 families with 22 or more species were among the 17 families that occurred in $90 \%$ or more of the localities; indeed, the 5 families with 38 or more species were among the seven families that occurred in $99 \%$ or more of the localities. Adding species incidence to the linear regression model improved the fit more than adding the average number of habitat types per species. The threevariable regression explained very little further variance (Table 2). These regressions were robust with respect to family-level taxonomy, very similar results (unpublished data) being produced following an older family-level taxonomy [20] even though the number of species changed in the families Formicariidae, Parulidae, Emberizidae and especially Furnariidae, Cotingidae, Thraupidae, Fringillidae and Cardinalidae; and two new families are currently recognized (Grallariidae and Tityridae).

\section{DISCUSSION}

Traditionally, assembly rules have been considered to be caused by ecological processes that operate locally. However, communities are strongly influenced by larger-scale and longer-term processes such as regional climatic history, historical biogeography, and speciation and extinction rates [21-25]. This perspective suggests that ecological assembly rules can be combined with macroevolutionary assembly rules to understand community patterns.

Because family incidence describes the frequency with which a family contributes species to communities, and number of species is a result of a macroevolutionary process (net speciation rates [26]), the high correlation between family incidence and number of species suggests a macroevolutionary assembly rule: monophyletic groups with higher net speciation rates contribute species to a larger number of communities.

The number of species-family incidence relationship may be seen as analogous to a species-area curve. A frequent limitation of species-area curves is that they often compare the species richnesses of mutually exclusive areas (such as islands, landscapes, biotic provinces or continents) which differ in habitat availability, resource availability and colonization history [27]. One approach to overcome this limitation has been to use geographically nested samples to study species-area relations [28-30], but this approach has the statistical limitation that geographically nested samples are not independent. By comparing the species-incidence relation of different taxonomic groups in a single region (e.g., different land bird families in Mexico), this analysis largely overcomes these limitations because 1) the different families overlap in their ranges, and ecological circumstances are shared in the areas of overlap, and 2) the different families are statistically independent.

Geographic speciation causes the species-area relationship at regional spatial scales [25] and may cause the number of species-family incidence relationship observed in Mexican land bird families. It is interesting that the slope of the number of species-family incidence relationship (1.11 when plotted in log-log space, which is standard when comparing species-area curves [25]) is comparable to the slope of interprovincial species-area curves (between 0.8 and 1.1), and is much higher than the slopes of species-area curves for islands or for patches within a region [25]. Interprovincial curves are the only species-area curves in which there is no or almost no overlap in species belonging to different samples (provinces); analogously, there is no overlap in species between samples (families) in the species-incidence relationship.

\section{IMPLICATIONS FOR COEVOLUTION}

The concept of coevolution has been criticized on the grounds that the long-term interactions necessary for species-specific coadaptation are rare [31]. Certain researchers (e.g., [32]) suggest that coevolution can be properly studied only by testing for species-specific coadaptations. On the other hand, other authors have supported the concept of diffuse coevolution (e.g., [33]), which proposes that coevolution can occur given long-term interactions between classes of organisms, i.e., above the species level.

The rule which establishes that speciose families contribute species to a large number of communities supports the concept of diffuse coevolution because it implies that certain monophyletic groups have had the potential for long-term interactions. For example, for Mexican landbirds, this rule suggests that throughout Mexico, vertebrates have been subjected to selection pressure imposed by predation by Accipitridae, and treehole-using animals have been freed from the need to create their own cavities due to the almost dependable presence of Picidae. Likewise, terrestrial seed-eaters have been faced with potential competition for food from Emberizidae, and flowering plants have had the possibility to interact with Trochilidae. In this way, this macroevolutionary assembly rule establishes the possibility of coevolution in the absence of species-specific coadaptation. The existence of such long-term associations between taxa above the species level suggests that certain coadaptations may not be recognizable through a strict species-level approach.

The number of species-family incidence pattern suggests that community composition is influenced not only by ecological assembly rules at the species level, but by a combination of ecological and macroevolutionary processes. Patterns in the composition of landbird communities in Mexico show that community composition is not entirely random. The mechanism for the assembly rule described in the present paper appears to be related to geographic speciation; therefore, this rule may apply as well to other groups of organisms and other regions and is not restricted to landbirds in Mexico.

\section{ACKNOWLEDGEMENTS}

H. Arita, M. C. Arizmendi, L. Bojórquez-Tapia, G. Ceballos, M. Equihua, M. Martínez-Ramos, R. Medellín, A. Navarro and E. Santana Castellón kindly commented on the manuscript and Mónica Pérez Villafaña and Adrián Gutiérrez Pérez helped create Fig. (1). Raúl Cueva del Castillo helped with the mathematical aspects of the classification of habitat types. This work benefitted greatly from their help. This work was carried out while the author received a CONACyT scholarship and a bonus from the Sistema Nacional de Investigadores.

\section{REFERENCES}

[1] Weiher E, Keddy PA. Assembly rules, null models, and trait dispersion: new questions from old patterns. Oikos 1995; 74: 159-64. 
[2] Belyea LR, Lancaster J. Assembly rules within a contingent ecology. Oikos 1999; 86: 402-16.

[3] Tregenza T. Building on the ideal free distribution. Adv Ecol Res 1995; 26: 253-302.

[4] Gómez de Silva H, Medellín RA. Are landbird assemblages functionally saturated?: an empirical test in Mexico. Oikos 2002; 96: $169-81$.

[5] Gómez de Silva H, Medellín RA. Evaluating completeness of species lists for conservation and macroecology: case-study of Mexican land birds. Conserv Biol 2001; 15: 1384-95.

[6] Brown JH. Macroecology. Chicago: University of Chicago Press 1995.

[7] Cornell Lab of Ornithology. The Clements Checklist of Birds of the World. 2008. [cited 2008 December 8]. Available from: http://www.birds.cornell.edu/clementschecklist/Copy\%20of $\% 20 \mathrm{Cl}$ ements\%20Checklist $\% 206.3 \% 20$ November\%202008.xls/view.

[8] Klicka J, Burns K, Spellman GM. Defining a monophyletic Cardinalini: a molecular perspective. Mol Phylogenet Evol 2007; 45: 1014-32.

[9] Howell SNG, Webb S. A guide to the birds of Mexico and northern Central America. Oxford, UK: Oxford University Press 1995.

[10] Alvarez del Toro M. Las aves de Chiapas: $2^{\text {nd }}$ ed. Tuxtla Gutiérrez, Chiapas: University of Nacional Autónoma de Chiapas 1980.

[11] Ehrlich PR, Dobkin DS, Wheye D. The birder's handbook: a field guide to the natural history of North American birds including all species that regularly breed north of Mexico. New York, NY: Simon \& Schuster 1988.

[12] Stiles FG, Skutch AF. 1989. A guide to the birds of Costa Rica. Ithaca, NY: Comstock 1989.

[13] Del Hoyo J, Elliott A, Sargatal J, Christie D, Eds. Handbook of the Birds of the World. Barcelona, Spain: Lynx Edicions 1992-2008; vols. 1-13.

[14] Sick H. Birds in Brazil: a natural history. Princeton, New Jersey: Princeton University Press 1993.

[15] Robinson SK. Habitat selection and foraging ecology of raptors in Amazonian Peru. Biotropica 1994; 26: 443-58.

[16] The Birds of North America Online [Homepage on the internet]. 2008 [cited 2008 Nov 26]. Available from http://bna.birds.cornell. edu/bna.
[17] Sánchez O, López G. A theoretical analysis of some indices of similarity as applied to biogeography. Folia Entomol Mex 1988; 75: 119-45.

[18] Patterson BD, Brown JH. Regionally nested patterns of species composition of granivorous rodent assemblages. J Biogeogr 1991; 18: 395-402.

[19] Hanski I. Dynamics of regional distribution: the core and satellite species hypothesis. Oikos 1982; 38: 210-21.

[20] A.O.U. The A.O.U. Check-list of North American Birds, $7^{\text {th }}$ ed. Washington, D.C: American Ornithologists' Union 1998.

[21] Ricklefs RE. Community diversity: relative roles of local and regional processes. Science 1987; 235: 167-71.

[22] Vrba ES. Mammals as a key to evolutionary theory. J Mammal 1992; 73: 1-28.

[23] Ricklefs RE, Schluter D, Eds. Species diversity in ecological communities. Chicago: University of Chicago Press 1993.

[24] Kelt DA, Taper ML, Meserve PL. Assessing the impact of competition on community assembly: a case study using small mammals. Ecology 1995; 76: 1283-96.

[25] Rosenzweig ML. Species diversity in space and time. Cambridge, UK: Cambridge University Press 1995.

[26] Vrba E.S. Macroevolutionary trends: new perspectives on the roles of adaptation and incidental effect. Science 1983;221:387-9.

[27] Graves GR, Gotelli NJ. Assembly of avian mixed-species flocks in Amazonia. Proc Natl Acad Sci USA 1993; 90: 1388-91.

[28] Palmer MW, White PS. Scale dependence and the species-area relationship. Am Nat 1994; 144: 717-24.

[29] Leitner WA, Rosenzweig ML. Nested species-area curves and stochastic sampling: a new theory. Oikos 1997; 79: 503-12.

[30] Lyons SK, Willig MR. A hemispheric assessment of scale dependence in latitudinal gradients of species richness. Ecology 1999; 80: 2483-91.

[31] Foster DR, Schoonmaker PK, Pickett STA. Insights from paleoecology to community ecology. Trends Ecol Evol 1990; 5: 119-22.

[32] Brooks DL, McLennan DA. Phylogeny, ecology and behavior. Chicago: University of Chicago Press 1991.

[33] Jordano P. Patterns of mutualistic interaction in pollination and seed dispersal: connectance, dependence, asymmetries and coevolution. Am Nat 1987; 129: 657-77.

(c) Héctor Gómez de Silva; Licensee Bentham Open.

This is an open access article licensed under the terms of the Creative Commons Attribution Non-Commercial License (http://creativecommons.org/licenses/ by-nc/3.0/) which permits unrestricted, non-commercial use, distribution and reproduction in any medium, provided the work is properly cited. 